\title{
Effects of Catecholamines, Exercise, and Nitroglycerin on the Normal and Ischemic Myocardium in Conscious Dogs
}

\author{
Stephen F. Vatner, Robert J. McRitchie, Peter R. Maroko, \\ Thomas A. Patrick, and Eugene Braunwald \\ From the Departments of Medicine, Harvard Medical School and Peter Bent \\ Brigham Hospital, and the Department of Cardiology, Children's Hospital \\ Medical Center, Boston, Massachusetts 02115 and the New England \\ Regional Primate Center, Southboro, Massachusetts 01772
}

A в S T R A C T The effects of isoproterenol, norepinephrine, dobutamine, exercise, and nitroglycerin on left ventricular diameter, pressure, velocity of shortening, $\mathrm{d} P / \mathrm{d} t, \mathrm{~d} P / \mathrm{d} t / P$, arterial pressure, left circumflex coronary blood flow, and coronary vascular resistance were examined in healthy conscious dogs with normal coronary perfusion and in the same animals after moderate global ischemia had been induced by partial occlusion of the left main coronary artery. In the normal nonischemic heart, all interventions improved left ventricular performance, as evidenced by increases in $\mathrm{d} P$ / $\mathrm{d} t / P$ and velocity at the same or lower left ventricular end-diastolic diameter. Interventions, which in the normal heart caused large increases in heart rate and myocardial contractility, e.g. isoproterenol and exercise, or which decreased coronary perfusion pressure, e.g. nitroglycerin or isoproterenol, elicited paradoxical responses in moderate global ischemia, i.e., left ventricular enddiastolic diameter and pressure rose, and $\mathrm{d} P / \mathrm{d} t / P$ and velocity fell substantially. On the other hand, norepinephrine, which increased coronary perfusion pressure along with myocardial contractility but did not increase heart rate, improved left ventricular function. Dobutamine, which did not alter heart rate or arterial pressure substantially while improving myocardial contractility, produced an intermediate response between that of norepinephrine and isoproterenol in the presence of moderate

This study was presented in part before the Association of American Physicians, Atlantic City, N. J., 1 May 1973. A preliminary report appeared in 1973. Clin. Res. 21: 719.

Dr. Vatner is an Established Investigator of The American Heart Association. Dr. McRitchie is an Overseas Research Fellow of the National Heart Foundation of Australia.

Received for publication 31 December 1973 and in revised form 13 May 1974. global myocardial ischemia. Thus, interventions that increase myocardial $\mathrm{O}_{2}$ requirements, by increasing heart rate and myocardial contractility without augmenting coronary perfusion pressure, can produce a paradoxical depression of ventricular function in the presence of global myocardial ischemia.

\section{INTRODUCTION}

Cardioactive sympathomimetic amines, exercise, and nitroglycerin all improve cardiac function, both in the normal heart and in the failing nonischemic heart (1-7). Despite frequent administration of catecholamines and nitroglycerin to patients with coronary atherosclerosis, their action in the presence of myocardial ischemia is not well established. While these interventions increase coronary blood flow and reduce coronary resistance in the normal heart, their effect might well be different when coronary blood flow is restricted (8). In fact, it has been recognized clinically that isoproterenol can result in a deterioration of cardiac performance in patients with severe coronary artery disease (9-14), and it has been shown experimentally that it can lead to extension of myocardial injury after experimental acute coronary artery occlusion $(15,16)$.

The goal of the present investigation was to determine the effects of myocardial ischemia on the response of the left ventricle to several sympathomimetic agents, to exercise, and to nitroglycerin in conscious dogs instrumented for radio telemetry of direct and continuous measurements of left ventricular $(\mathrm{LV})^{1}$ dimensions, pressures, $\mathrm{d} P / \mathrm{d} t$, velocity of fiber shortening, and coronary blood flow. Since the actions of these several stimuli on heart rate and peripheral vascular resistance

\footnotetext{
${ }^{1}$ Abbreviations used in this paper: $D$, left ventricular diameter; $L V$, left ventricular; $P$, left ventricular pressure.
} 
may be as important as their direct inotropic effects on altering the function of the ischemic heart, a number of positive inotropic interventions with varying associated chronotropic and pressor effects were compared. Isoproterenol, a pure beta adrenergic agonist which increases contractility in combination with strongly positive chronotropic and hypotensive effects, was compared with: (a) exercise, which increases contractility and heart rate but does not reduce arterial pressure; $(b)$ dobutamine, a beta adrenergic agonist that increases contractility with relatively slight effects on heart rate and arterial pressure ${ }^{2}$ (5); (c) norepinephrine, which increases contractility and arterial pressure but not heart rate (4); and $(d)$ nitroglycerin, which causes slight reflex increases in contractility and heart rate secondary to its systemic hypotensive action (7).

\section{METHODS}

11 mongrel dogs, weighing between 25 and $35 \mathrm{~kg}$, were anesthetized with i.v. Na pentobarbital, $30 \mathrm{mg} / \mathrm{kg}$. Through a thoracotomy in the fifth left intercostal space, miniature pressure gauges (Konigsberg P22, Konigsberg Instruments, Inc., Pasadena, Calif.) were implanted within the left ventricle through a stab wound in the apex; ultrasonic diameter transducers ${ }^{3}$ were implanted on opposing anterior and posterior endocardial surfaces across the transverse diameter of the left ventricle, and Doppler ultrasonic flow transducers were placed around the left circumflex coronary artery; hydraulic occluders were implanted around the left main coronary artery, and heparin-filled catheters were chronically implanted in the thoracic aorta.

The miniature pressure gauges were calibrated in vivo against a calibrated Statham P23 Db strain gauge manometer (Statham Instruments, Inc., Oxnard, Calif.). At autopsy, the position of the ventricular gauges within the ventricular cavity was confirmed. Arterial pressure was sampled with the previously implanted heparin-filled Tygon catheter (Norton Co., Plastics and Synthetics Div., Akron, Ohio) and measured with a Statham P23 Db strain gauge manometer. Left circumflex coronary blood flow was measured with an ultrasonic Doppler flowmeter. This system, which has been described in detail previously, has a reliable zero reference $(17,18)$, and in these experiments, electrical zero blood flow was determined repeatedly and was confirmed by calibration when the animal was sacrificed. The relationship between velocity, as measured by the Doppler flowmeter, and volume flow is linear as long as the cross-sectional area of the blood vessel within the transducer remains constant. This linear relationship between velocity and volume flow has been demonstrated repeatedly previously and confirmed by means of timed collections of blood flow (18). At autopsy, it was observed that the vessels were firmly adherent to the flow transducers through a fibrous scar which minimized changes in the cross-sectional area of the vessel within the flow transducers.

An improved ultrasonic transit time dimension gauge was used to measure LV diameter (19); it measures the

\footnotetext{
${ }^{2}$ Tuttle, R. R., and J. Mills. Dobutamine: development of a new catecholamine to selectively increase cardiac contractility. Manuscript submitted for publication.

${ }^{8}$ Construction details available from authors.
}

transit time of acoustic impulses traveling at the sonic velocity of approximately $1.5 \times 10^{6} \mathrm{~mm} / \mathrm{s}$ between the 5 or $3 \mathrm{MHz}$ piezoelectric crystals sutured to the LV endocardium at opposing sites. It was calibrated by substituting signals of known time duration from a calibrated pulse generator. A voltage proportional to transit time was recorded and calibrated in terms of crystal separation. In this manner, a measure of the internal diameter of the left ventricle was continuously recorded. At a constant temperature, the drift of the instrument is less than 0.15 $\mathrm{mm} / \mathrm{h}$, and its frequency response is flat to $60 \mathrm{~Hz}$. The correlation between LV diameter measurement and LV volume changes is good under many circumstances in the normal heart $(6,20)$. Of course, it must be kept in mind that the volume changes as the cube function of the diameter.

Experiments were conducted 2-4 wk after operation. While the conscious unsedated dogs rested quietly, control records of $\mathrm{LV}$ diameter $(D)$ and pressure $(P)$, rate of change of diameter $(\mathrm{d} D / \mathrm{d} t)$, i.e., the velocity of myocardial shortening, the rate of change of pressure $(\mathrm{d} P / \mathrm{d} t)$, left circumflex coronary blood flow, arterial pressure, and heart rate were obtained. These variables were continuously recorded during all interventions. Isoproterenol, $0.4 \mu \mathrm{g} /$ $\mathrm{kg} / \mathrm{min}$ (nine dogs), nitroglycerin, $15 \mu \mathrm{g} / \mathrm{kg} / \mathrm{min}$ (nine dogs) dobutamine, $40 \mu \mathrm{g} / \mathrm{kg} / \mathrm{min}$ (six $\operatorname{dogs}$ ), and norepinephrine, $0.8 \mu \mathrm{g} / \mathrm{kg} / \mathrm{min}$ (five dogs) were infused intravenously. Values obtained in a steady state $1-3 \mathrm{~min}$ after beginning of infusion were compared with preinfusion control values. The animals were studied without inflation of the hydraulic occluders, i.e., in the absence of ischemia and then after the occluder on the left main coronary artery had been inflated to reduce coronary flow by an amount that resulted in minimal impairment of $\mathrm{LV}$ function at rest, a condition referred to as moderate global ischemia. Left circumflex coronary flow was used to measure the extent of ischemia produced. The same reduction of coronary flow, which averaged $30 \pm 1 \%$, was induced in each animal in each experiment. Control coronary occlusions were carried out to determine the effects of partial left main coronary occlusions alone on resting hemodynamics for $15 \mathrm{~min}$. Three dogs were studied with dobutamine, $40 \mu \mathrm{g} / \mathrm{kg} / \mathrm{min}$, and isoproterenol, $0.2 \mu \mathrm{g} / \mathrm{kg} / \mathrm{min}$, in the presence of more severe ischemia, i.e., the occluder on the left main coronary artery had been inflated to reduce control coronary flow by $50 \%$. There was no residual effect of ischemia as could be detected with these techniques. The effects of interventions were reproducible from day to day.

In order to study the effects of exercise, measurements were radiotelemetered from five dogs standing at rest and while running at 4-6 mph with and without left main coronary artery occlusion (19). Studies were repeated on separate days, randomizing the order of the interventions. The effects of interventions were found to be reproducible from day to day. Identical experiments on separate days were averaged for each animal. In three dogs, using local anesthesia, a balloon catheter was introduced into the aorta through the femoral artery. It was advanced into the thoracic aorta, approximately $35-40 \mathrm{~cm}$. In these experiments, when arterial pressure fell as a consequence of coronary occlusion, it could be returned to control by inflation of the intra-aortic balloon.

After the experiments outlined above were completed, three of the dogs were anesthetized with pentobarbital $\mathrm{Na}$, $30 \mathrm{mg} / \mathrm{kg}$. Through another left thoracotomy, electromagnetic flow probes (Statham SP2200, Statham Instruments, 
Inc.) were placed around the anterior descending coronary artery. The effects of partial left main coronary artery occlusion were then assessed on blood flows measured simultaneously in the left circumflex and anterior descending coronary arteries.

Data were recorded on a multichannel tape recorder and played back on a direct writing oscillograph at a paper speed of $100 \mathrm{~mm} / \mathrm{s}$. A cardiotachometer, triggered by the signal from the pressure pulse, provided instantaneous and continuous records of heart rate. Electronic RC filters with 2 -s time constants were used to derive mean arterial blood pressure and mean left circumflex coronary blood flow. Mean and late diastolic coronary vascular resistances were calculated as the quotients of mean and late diastolic arterial pressures and coronary blood flows, respectively. Continuous records of $\mathrm{d} P / \mathrm{d} t$ and $\mathrm{d} D / \mathrm{d} t$ were derived from the LV pressure and diameter signals by using Philbrick operational amplifiers (Teledyne Philbrick, Dedham, Mass.), connected as differentiators and having frequency responses of 60 and $30 \mathrm{~Hz}$, respectively. A triangular wave signal with known slope (rate of change) was substituted for pressure and diameter signals to calibrate directly the $\mathrm{d} P / \mathrm{d} t$ and $\mathrm{d} D / \mathrm{d} t$ channels.

The effects of interventions on myocardial force-velocity relations were assessed by determining their effects on the velocity of shortening and intraventricular pressure at an identical ventricular diameter (isolength point), i.e. $V_{1 \text { so }}$ by the technique described in detail previously $(4-7,21)$. All isolength points were obtained during the first onethird of ejection. For interventions where cardiac size varied greatly, e.g. isoproterenol and nitroglycerin, isolength points could not be found, and peak velocity measurements were reported. In addition, the effects on peak $\mathrm{d} P / \mathrm{d} t$ and the quotient of $\mathrm{d} P / \mathrm{d} t$ and developed pressure (LV) isovolumic minus end-diastolic pressure), i.e. $\mathrm{d} P / \mathrm{d} t /$ $P$, were examined. The same level of developed pressure which occurred during isometric contraction, before and after each intervention, was used for this calculation, and $\mathrm{d} P / \mathrm{d} t$ and $P$ were determined at that level of pressure. This technique for evaluating the myocardial contractile state has also been described in detail previously $(4-7,22)$.

Average and SEM values were calculated. Control and response values were compared in the same animals by using a paired $t$ test (23). Changes from control with interventions in normal and ischemic states were compared by using the paired $t$ test. (23).

\section{RESULTS}

Partial occlusion of the left main coronary artery produced slight changes from control in resting hemodynamics (Table I). The increases in heart rate and $\mathrm{LV}$ end-diastolic diameter and pressure and the decreases in coronary blood flow, $\mathrm{d} P / \mathrm{d} t, \mathrm{~d} P / \mathrm{d} t / P$, and velocity were significant. The hemodynamic values at rest in the presence of the ischemic state remained stable for at least $15 \mathrm{~min}$. Accordingly, it was possible to compare the effects of the various interventions on the same heart in the presence and absence of global ischemia.

To determine the effects of partial left main coronary artery occlusion on left anterior descending coronary blood flow, left anterior descending coronary blood flow was measured in three dogs. Partial occlusion of the left main coronary artery, sufficient to produce what has been
TABLE I

Resting Dynamics in the Normal and Ischemic Myocardium

\begin{tabular}{|c|c|c|}
\hline & $\begin{array}{l}\text { Normal } \pm \mathrm{SE} \\
\quad(n=9)\end{array}$ & $\begin{array}{c}\text { Global } \\
\text { ischemia } \pm \mathrm{SE} \\
(n=9)\end{array}$ \\
\hline Heart rate, beats/min & $74 \pm 3$ & $104 \pm 3^{*}$ \\
\hline $\begin{array}{l}\text { Mean arterial pressure, } \mathrm{mm} \mathrm{Hg} \\
\text { Mean left circumflex }\end{array}$ & $96 \pm 2$ & $98 \pm 2$ \\
\hline coronary flow, $\mathrm{ml} / \mathrm{min}$ & $38 \pm 2$ & $26 \pm 2^{*}$ \\
\hline LV diameters, $m m$ & & \\
\hline $\begin{array}{l}\text { End-diastolic } \\
\text { End-systolic }\end{array}$ & $\begin{array}{l}35.1 \pm 0.7 \\
26.7 \pm 0.7\end{array}$ & $\begin{array}{l}36.4 \pm 0.7^{*} \\
27.6 \pm 0.7\end{array}$ \\
\hline \multicolumn{3}{|l|}{ LV pressures, $m m ~ H g$} \\
\hline Peak & $123 \pm 3$ & $125 \pm 3$ \\
\hline Isolength & $118 \pm 3$ & $120 \pm 3$ \\
\hline End-diastolic & $8 \pm 1$ & $10 \pm 1^{*}$ \\
\hline Peak $\mathrm{d} P / \mathrm{d} t, m m H g / s$ & $3,440 \pm 120$ & $3,210 \pm 140^{*}$ \\
\hline $\mathrm{d} P / \mathrm{d} t / \mathrm{P}, s^{-1}$ & $60 \pm 2$ & $55 \pm 2^{*}$ \\
\hline \multicolumn{3}{|l|}{ Velocity, $\mathrm{mm} / \mathrm{s}$} \\
\hline Peak & $79 \pm 3$ & $73 \pm 3^{*}$ \\
\hline Isolength & $75 \pm 3$ & $70 \pm 3^{*}$ \\
\hline
\end{tabular}

* Significantly different from normal, $P<0.01$.

termed moderate global ischemia, produced proportional reductions of flow in the left anterior descending and left circumflex coronary arteries, suggesting that reductions in the left circumflex coronary blood flow recorded during the experiments with left main coronary artery occlusion reflected proportional reductions in the perfusion of the entire left ventricle.

\section{Effects of isoproterenol (nine dogs)}

Normal response (nonischemic heart). Isoproterenol infusion increased heart rate and reduced mean and late diastolic arterial pressures (Table II). Mean and late diastolic coronary blood flow rose, while mean and late diastolic coronary vascular resistances fell from $2.57 \pm$ 0.15 and $1.95 \pm 0.12$ to $0.83 \pm 0.03$ and $0.62 \pm 0.03 \mathrm{~mm} \mathrm{Hg}$ / $\mathrm{ml} / \mathrm{min}$, respectively Both $\mathrm{LV}$ end-diastolic and endsystolic diameters fell, as did LV end-diastolic pressure (Fig 1). Peak $\mathrm{d} P / \mathrm{d} t, \mathrm{~d} P / \mathrm{d} t / P$, and peak velocity all rose substantially (Table II).

Partial left main coronary occlusion (moderate global ischemia). As in the normal heart, isoproterenol increased heart rate and reduced arterial pressure, but in contrast to its action in the absence of coronary occlusion, isoproterenol did not alter left circumflex coronary blood flow significantly in the presence of moderate global ischemia (Table II). After an initial transient improvement in LV function, isoproterenol infusion resulted in a picture of acute cardiac failure (Fig. 1). LV end-diastolic and end-systolic diameters and LV end-diastolic pressure rose above control levels, while contractility, instead of rising, actually fell drastically (Fig. 2). The effects of isoproterenol on coronary blood 
TABLE II

Effects, of Isoproterenol, Exercise, Dobutamine, Norepinephrine,

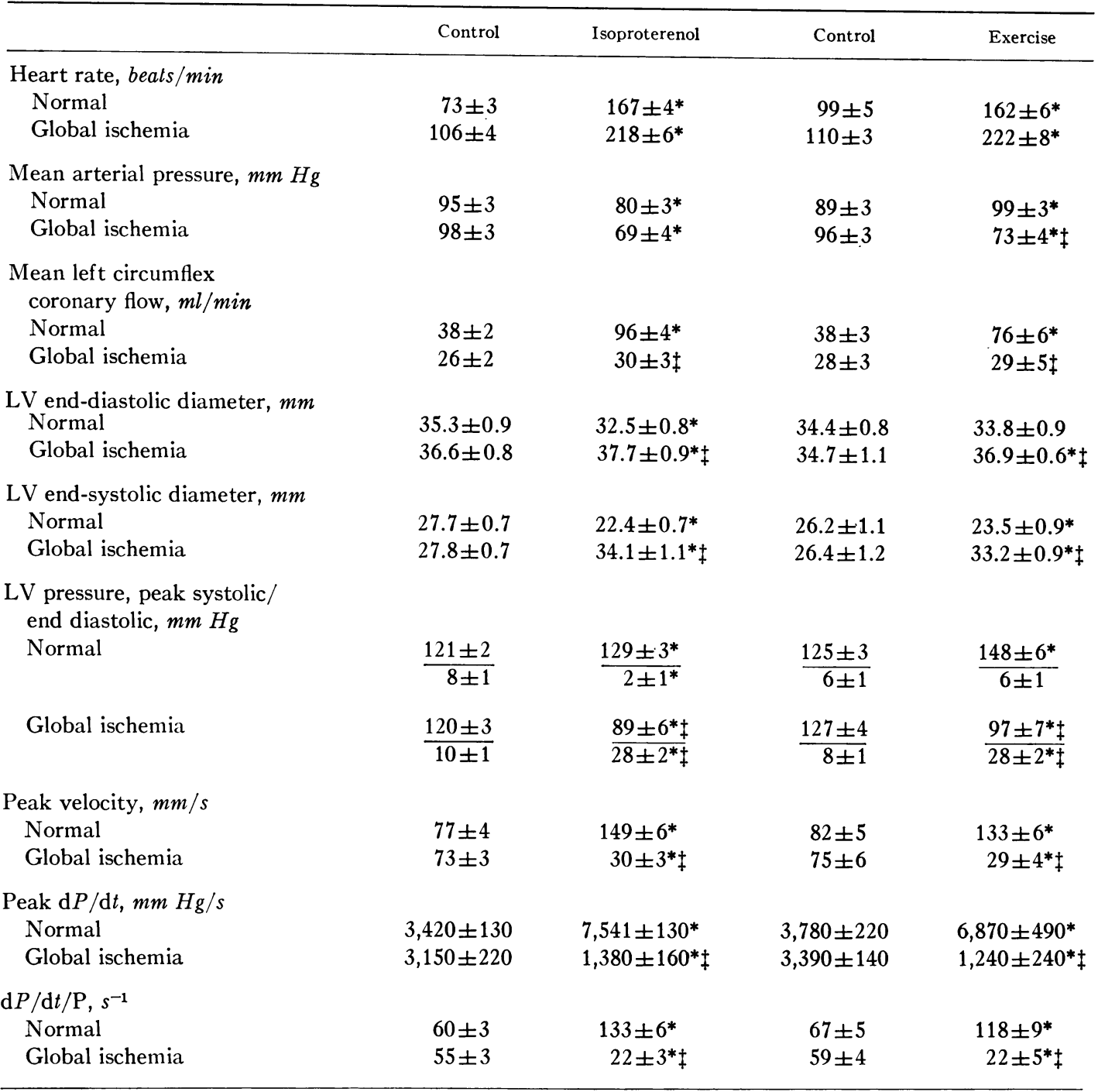

* Significant change from control, $P<0.01$.

$\ddagger$ Change from control in global ischemia significantly different from normal response, $P<0.01$.

flow, LV diameters, end-diastolic pressure, peak $\mathrm{d} P / \mathrm{d} t$, $\mathrm{d} P / \mathrm{d} t / P$, and velocity were significantly different from the effects observed in the control state $(P<0.01)$ (Fig. 2). When the occlusion was relieved, and with continuation of isoproterenol, LV function improved rapidly, as had occurred with isoproterenol in the nonischemic heart (Fig. 1). In three dogs, half the isoproterenol dose $(0.2 \mu \mathrm{g} / \mathrm{kg} / \mathrm{min})$ resulted in the same picture of acute cardiac failure with more intense ischemia, i.e., coronary flow reduction of $50 \%$.

When arterial pressure was maintained at control levels by inflating the intra-aortic balloon during the infusion of isoproterenol, the brief initial period of im- proved LV function was prolonged. At 1-2 min after beginning isoproterenol infusion, i.e., at the time of acute cardiac decompensation in the experiments without balloon inflation, improved LV function was still observed when the balloon was inflated. At this time heart rate was elevated to 174 beats/min, LV end-diastolic size was slightly reduced, and end-systolic size was reduced by a greater extent than end-diastolic, while myocardial contractility, as reflected by peak $\mathrm{d} P / \mathrm{d} t$, $\mathrm{d} P / \mathrm{d} t / P$, and peak velocity, remained elevated; $\mathrm{d} P /$ $\mathrm{d} t / P$ rose from an average of 56 to $72 \mathrm{~s}^{-1}$. Nevertheless, with balloon inflation, impairment of LV function appeared after approximately $5 \mathrm{~min}$ of isoproterenol infu- 
and Nitroglycerin in the Normal and Ischemic Heart

\begin{tabular}{|c|c|c|c|c|c|}
\hline Control & Dobutamine & Control & Norepinephrine & Control & Nitroglycerin \\
\hline $\begin{array}{r}75 \pm 5 \\
110 \pm 4\end{array}$ & $\begin{array}{r}90 \pm 4^{*} \\
126 \pm 5^{*}\end{array}$ & $\begin{array}{r}73 \pm 5 \\
100 \pm 5\end{array}$ & $\begin{array}{l}64 \pm 4^{*} \\
92 \pm 5\end{array}$ & $\begin{array}{r}76 \pm 4 \\
105 \pm 4\end{array}$ & $\begin{array}{l}102 \pm 4^{*} \\
149 \pm 6^{*}\end{array}$ \\
\hline $\begin{array}{r}99 \pm 3 \\
101 \pm 4\end{array}$ & $\begin{array}{l}110 \pm 2^{*} \\
119 \pm 4^{*}\end{array}$ & $\begin{array}{l}92 \pm 3 \\
95 \pm 4\end{array}$ & $\begin{array}{l}138 \pm 9^{*} \\
133 \pm 8^{*}\end{array}$ & $\begin{array}{l}97 \pm 2 \\
97 \pm 3\end{array}$ & $\begin{array}{l}82 \pm 2^{*} \\
77 \pm 3^{*}\end{array}$ \\
\hline $\begin{array}{l}39 \pm 3 \\
26 \pm 3\end{array}$ & $\begin{array}{l}59 \pm 4^{*} \\
32 \pm 3_{+}^{+}\end{array}$ & $\begin{array}{l}36 \pm 2 \\
23 \pm 3\end{array}$ & $\begin{array}{l}48 \pm 5^{*} \\
40 \pm 5^{*}\end{array}$ & $\begin{array}{l}37 \pm 2 \\
29 \pm 2\end{array}$ & $\begin{array}{l}51 \pm 2^{*} \\
12 \pm 2^{*} \ddagger\end{array}$ \\
\hline $\begin{array}{l}36.4 \pm 0.7 \\
37.0 \pm 0.8\end{array}$ & $\begin{array}{l}36.6 \pm 0.8 \\
37.8 \pm 0.7\end{array}$ & $\begin{array}{l}36.1 \pm 0.9 \\
37.5 \pm 0.7\end{array}$ & $\begin{array}{l}36.6 \pm 0.9 \\
39.5 \pm 0.5^{*}\end{array}$ & $\begin{array}{l}34.8 \pm 0.8 \\
35.9 \pm 0.7\end{array}$ & $\begin{array}{l}31.9 \pm 0.9^{*} \\
36.7 \pm 0.6^{*}\end{array}$ \\
\hline $\begin{array}{l}27.6 \pm 0.8 \\
28.7 \pm 0.8\end{array}$ & $\begin{array}{l}24.5 \pm 0.5^{*} \\
27.5 \pm 0.5 \ddagger\end{array}$ & $\begin{array}{l}27.0 \pm 0.9 \\
28.2 \pm 0.8\end{array}$ & $\begin{array}{l}24.7 \pm 0.9^{*} \\
28.3 \pm 1.1 \ddagger\end{array}$ & $\begin{array}{l}26.3 \pm 0.7 \\
27.4 \pm 0.7\end{array}$ & $\begin{array}{l}23.7 \pm 0.9^{*} \\
31.8 \pm 0.9^{*+}\end{array}$ \\
\hline$\frac{125 \pm 2}{9 \pm 1}$ & $\frac{151 \pm 5^{*}}{8 \pm 1}$ & $\frac{123 \pm 3}{8 \pm 1}$ & $\frac{186 \pm 6^{*}}{11 \pm 1^{*}}$ & $\frac{124 \pm 3}{8 \pm 1}$ & $\frac{113 \pm 3^{*}}{3 \pm 1^{*}}$ \\
\hline$\frac{127 \pm 3}{11 \pm 1}$ & $\frac{153 \pm 5^{*}}{11 \pm 1}$ & $\frac{125 \pm 3}{10 \pm 1}$ & $\frac{169 \pm 7^{*}}{15 \pm 1^{*}}$ & $\frac{122 \pm 3}{10 \pm 1}$ & $\frac{99 \pm 3^{*+}}{15 \pm 1_{+}^{*+}}$ \\
\hline $\begin{array}{l}74 \pm 5 \\
68 \pm 5\end{array}$ & $\begin{array}{r}135 \pm 6^{*} \\
80 \pm 6 \ddagger\end{array}$ & $\begin{array}{l}76 \pm 6 \\
70 \pm 4\end{array}$ & $\begin{array}{r}116 \pm 4^{*} \\
87 \pm 5^{*+}\end{array}$ & $\begin{array}{l}78 \pm 3 \\
73 \pm 3\end{array}$ & $\begin{array}{l}90 \pm 3^{*} \\
52 \pm 5^{* *}\end{array}$ \\
\hline $\begin{array}{l}3,460 \pm 140 \\
3,150 \pm 150\end{array}$ & $\begin{array}{l}7,780 \pm 610^{*} \\
4,160 \pm 850 \ddagger\end{array}$ & $\begin{array}{l}3,500 \pm 200 \\
3,260 \pm 190\end{array}$ & $\begin{array}{l}7,380 \pm 310^{*} \\
5,710 \pm 770^{*+}\end{array}$ & $\begin{array}{l}3,400 \pm 130 \\
3,250 \pm 110\end{array}$ & $\begin{array}{l}3,740 \pm 110^{*} \\
2,240 \pm 170^{*}+\end{array}$ \\
\hline $\begin{array}{l}59 \pm 3 \\
53 \pm 3\end{array}$ & $\begin{array}{c}129 \pm 10^{*} \\
62 \pm 7 \ddagger\end{array}$ & $\begin{array}{l}61 \pm 5 \\
57 \pm 5\end{array}$ & $\begin{array}{l}120 \pm 7^{*} \\
90 \pm 13_{+}^{*+}\end{array}$ & $\begin{array}{l}60 \pm 2 \\
57 \pm 2\end{array}$ & $\begin{array}{l}66 \pm 2^{*} \\
38 \pm 4_{+}^{*+}\end{array}$ \\
\hline
\end{tabular}

sion, instead of after approximately $1 \mathrm{~min}$ of infusion, as occurred when arterial pressure was allowed to decline with isoproterenol infusion.

\section{Effects of exercise (five dogs)}

Normal response. Exercise increased heart rate to approximately the same extent as did isoproterenol, but with exercise, mean and late diastolic arterial pressures increased slightly (Table II). Mean and late diastolic left circumflex coronary flows increased, while mean and late diastolic coronary resistances fell from 2.42 0.22 and $2.35 \pm 0.55$ to $1.35 \pm 0.14$ and $0.93 \pm 0.10 \mathrm{~mm}$ $\mathrm{Hg} / \mathrm{ml} / \mathrm{min}$, respectively $(P<0.01)$. Peak and isolength systolic LV pressures and mean arterial pressure increased. LV end-diastolic pressure and diameter did not change significantly, but $\mathrm{LV}$ end-systolic diameter fell from $26.2 \pm 1.1$ to $23.5 \pm 0.9 \mathrm{~mm}(P<0.01)$. Contractility, as reflected in peak $\mathrm{d} P / \mathrm{d} t, \mathrm{~d} P / \mathrm{d} t / P$, and isolength velocity rose to a similar extent as with isoproterenol (Fig. 3).

Partial left main coronary artery occlusion. As had occurred with isoproterenol, when exercise was carried out in the presence of moderate global ischemia, initial improvement in LV function occurred that was rapidly reversed, and this resulted in a picture of acute cardiac failure (Fig. 4). Heart rate still rose, but mean 


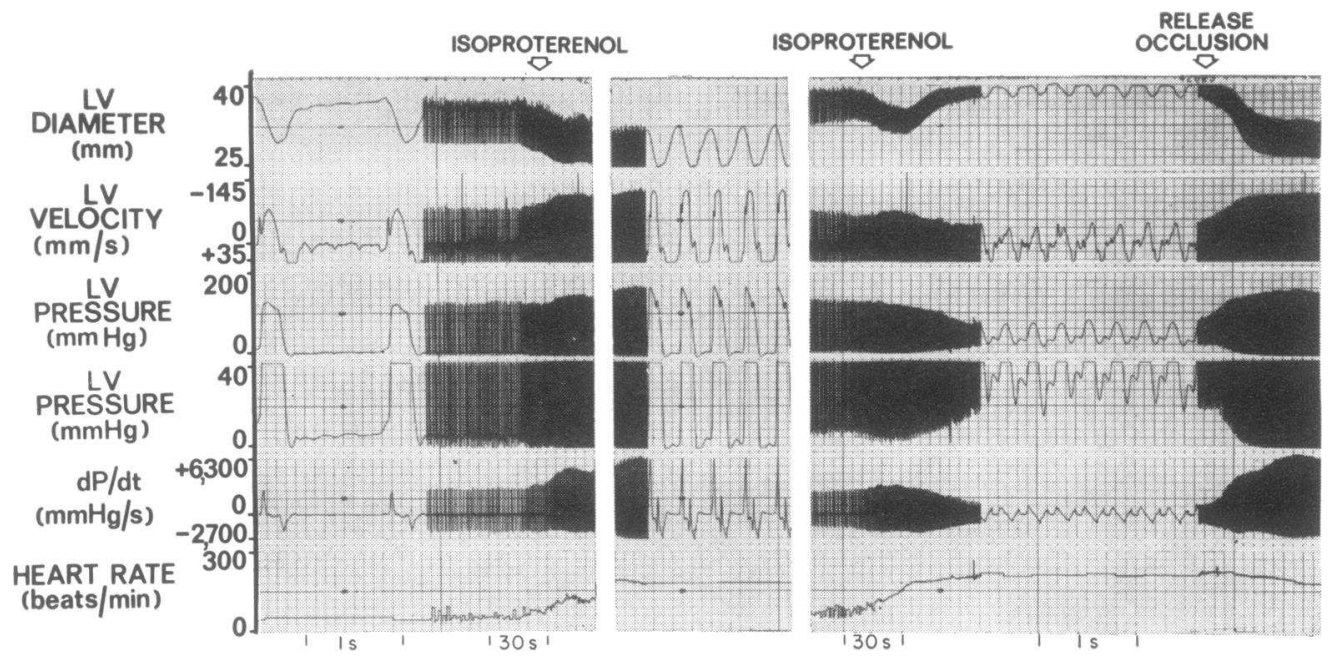

FIgURE 1 Typical response to isoproterenol, $0.4 \mu \mathrm{g} / \mathrm{kg} / \mathrm{min}$, in a normal conscious dog (left panels). Isoproterenol infusion (arrow) increased heart rate and myocardial contractility in the normal heart as reflected by increases in velocity and $\mathrm{d} P / \mathrm{d} t$ while decreasing $\mathrm{LV}$ enddiastolic diameter. Phasic wave forms at rapid paper speed during control (left) can be compared with those during the steady-state peak response (middle panel). This response can be contrasted with that after partial occlusion of the left main coronary artery in the same dog (right panel). With moderate global ischemia at rest, isoproterenol infusion caused an initial transient improvement in LV function, which was rapidly followed by acute cardiac decompensation, i.e., substantial increases in LV end-diastolic diameter and even greater increases in LV end-systolic diameter, reflecting a marked reduction in stroke volume that occurred in association with a striking decrease in myocardial contractility as reflected by reductions in velocity and $\mathrm{d} P / \mathrm{d} t$. With release of occlusion (arrow) and maintenance of isoproterenol, a more normal response reappeared.

arterial pressure fell, while mean left circumflex coronary flow remained constant (Table II). LV end-diastolic and end-systolic diameters rose, as did LV enddiastolic pressure. Instead of rising, contractility fell, as reflected by decreases in peak $\mathrm{d} P / \mathrm{d} t, \mathrm{~d} P / \mathrm{d} t / P$, and isolength velocity ( Fig. 3 ).

The change induced by exercise on LV pressures and diameters and contractility were all significantly different in the presence of moderate global ischemia from those observed in the nonischemic heart. When the occlusion was relieved and the exercise was discontinued, normal function rapidly reappeared.

\section{Effects of dobutamine (six dogs)}

Normal response. Dobutamine increased heart rate and mean and late diastolic arterial pressures only slightly (Table II). Mean and late diastolic left circumflex coronary blood flows rose, while mean and late diastolic coronary vascular resistances fell from 2.64 0.26 and $1.87 \pm 0.11$ to $2.03 \pm 0.21$ and $1.35 \pm 0.12 \mathrm{~mm} \mathrm{Hg}$ / $\mathrm{ml} / \mathrm{min}$, respectively. LV end-diastolic pressure and diameter did not change significantly, but end-systolic diameter fell from $27.6 \pm 0.8$ to $24.5 \pm 0.5 \mathrm{~mm}$, and $\mathrm{LV}$ peak systolic pressure rose. The augmentation of con- tractility (Fig. 5) was comparable to that which occurred with isoproterenol and exercise (Table II).

Partial left main coronary artery occlusion. Dobutamine infusion increased heart rate and mean arterial pressure by similar amounts as in the nonischemic heart (Table II). However, mean left circumflex coronary blood flow, LV end-diastolic diameter and pressure did not change significantly, LV end-systolic diameter fell only slightly, while contractility rose slightly but not significantly (Fig. 5). Thus, in the presence of moderate global ischemia, dobutamine produced little change in myocardial contractility, a response which differed significantly $(P<0.01)$ from that which occurred with the same dose of the drug in the nonischemic heart. In three dogs when more severe global ischemia was induced, dobutamine depressed LV function, as had occurred with isoproterenol and exercise in moderate ischemia. However, with moderate global ischemia, dobutamine clearly was not as deleterious as isoproterenol. In three dogs in which little change occurred with dobutamine in the presence of moderate global ischemia, a picture of acute depression of cardiac function occurred when isoproterenol was substituted for dobutamine (Fig. 6). 

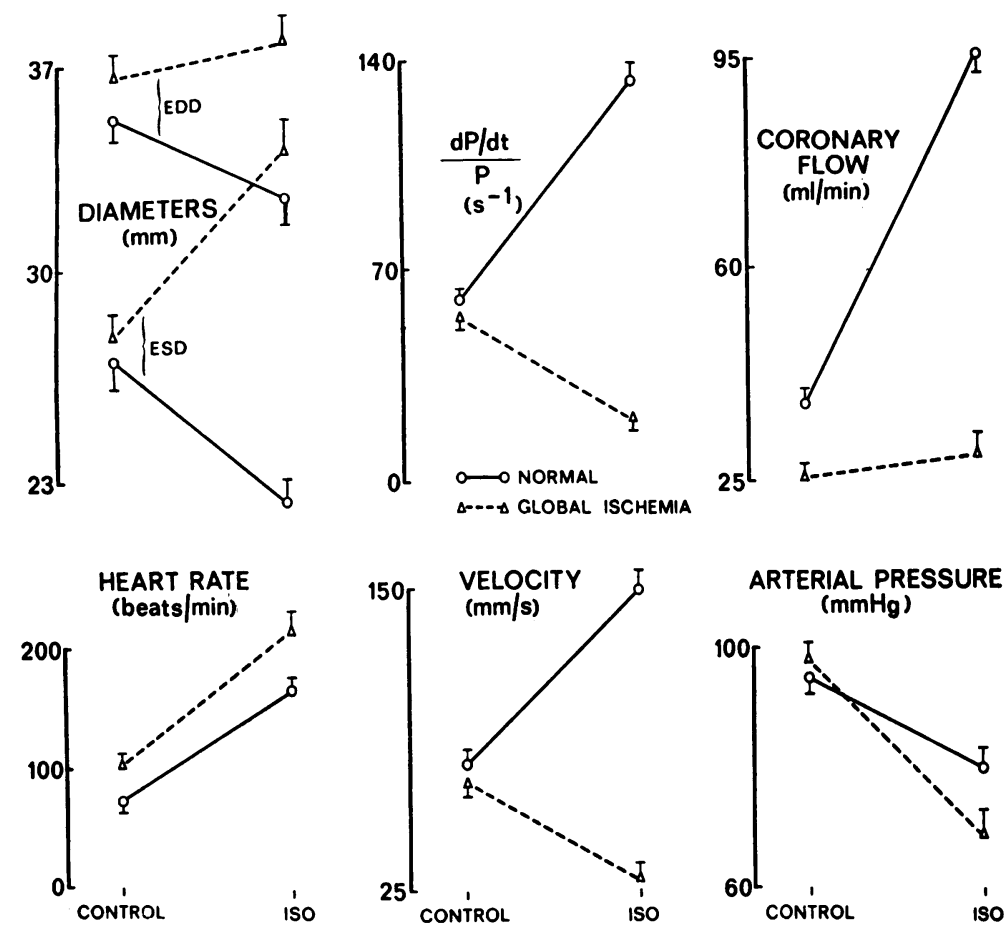

Figure 2 Comparison of average \pm SEM values before treatment and with isoproterenol (ISO) infusion in the same dogs studied in the nonischemic condition (circles and solid lines) and with moderate global myocardial ischemia at rest (triangles and broken lines). Note the paradoxical responses for LV end-diastolic (ED) and end-systolic (ES) diameters (D), $\mathrm{d} P / \mathrm{d} t / \mathrm{P}$, velocity, and coronary flow.
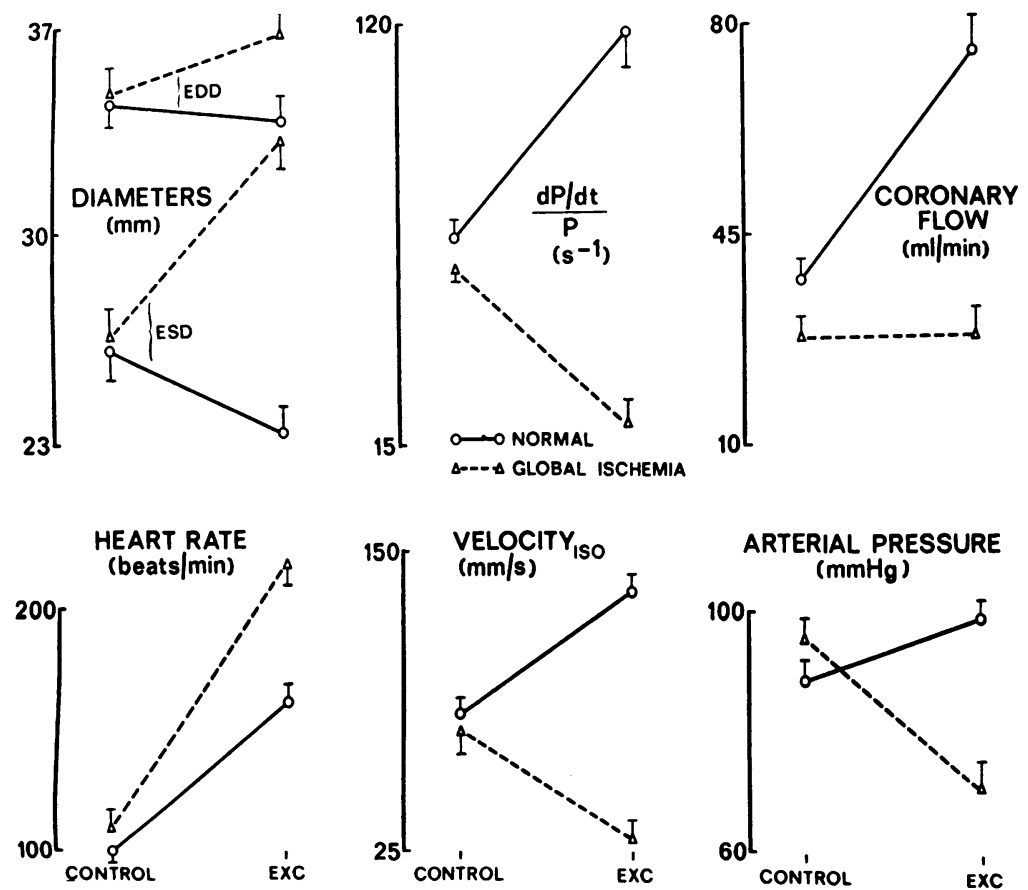

Figure 3 Comparison of average \pm SEM values before and during exercise in the same dogs studied in the nonischemic condition (circles and solid lines) and with moderate global myocardial ischemia (triangles and broken lines). Note the paradoxical responses for LV diameters, $\mathrm{d} P / \mathrm{d} t / \mathrm{P}$, velocity, and coronary flow. See Fig. 2 for abbreviations. 

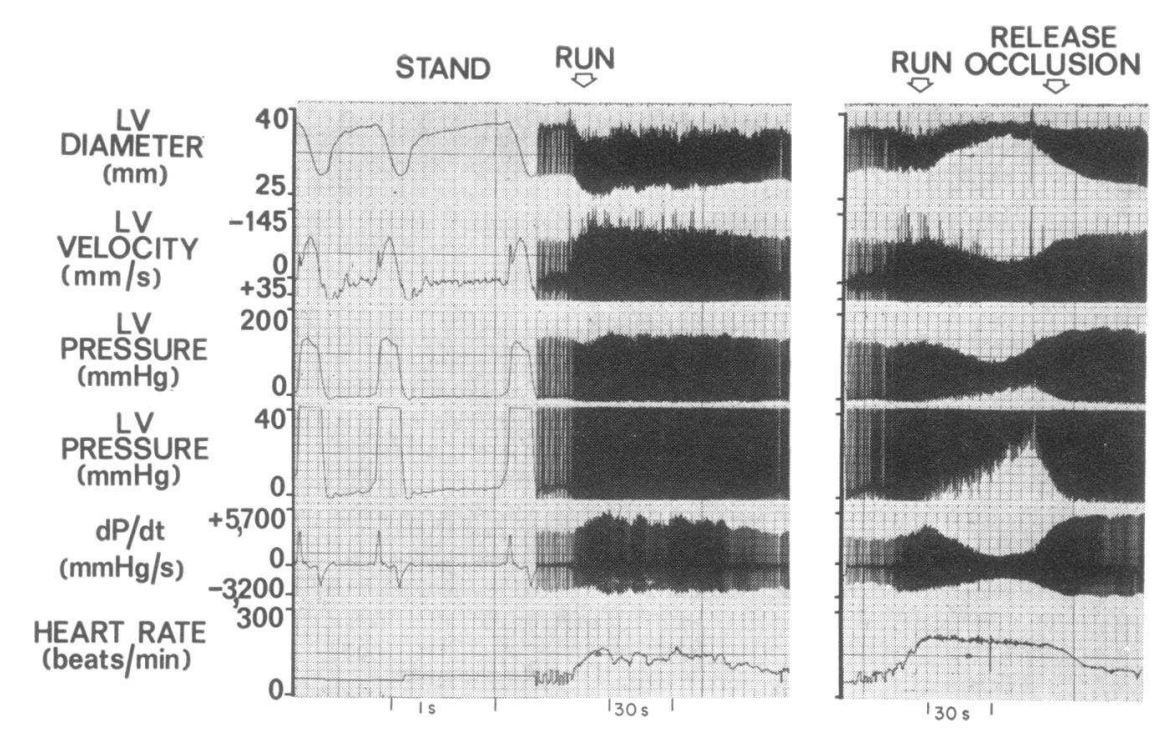

FIGURE 4 Typical response to mild exercise in a normal, conscious dog (left panel). Exercise increased heart rate and myocardial contractility as reflected by increases in velocity and $\mathrm{d} P / \mathrm{d} t$, and decreased LV end-systolic diameter, while LV end-diastolic diameter remained constant or slightly decreased as in this case. In the right panel, a typical response to mild exercise in the same dog is shown, but in this case in the presence of moderate global myocardial ischemia at rest. With exercise, after an initial transient improvement, acute LV decompensation occurred as reflected by increases in LV end-diastolic diameter and pressure, $\mathrm{LV}$ end-systolic diameter, and decreases in stroke excursion, velocity, and $\mathrm{d} P / \mathrm{d} t$.
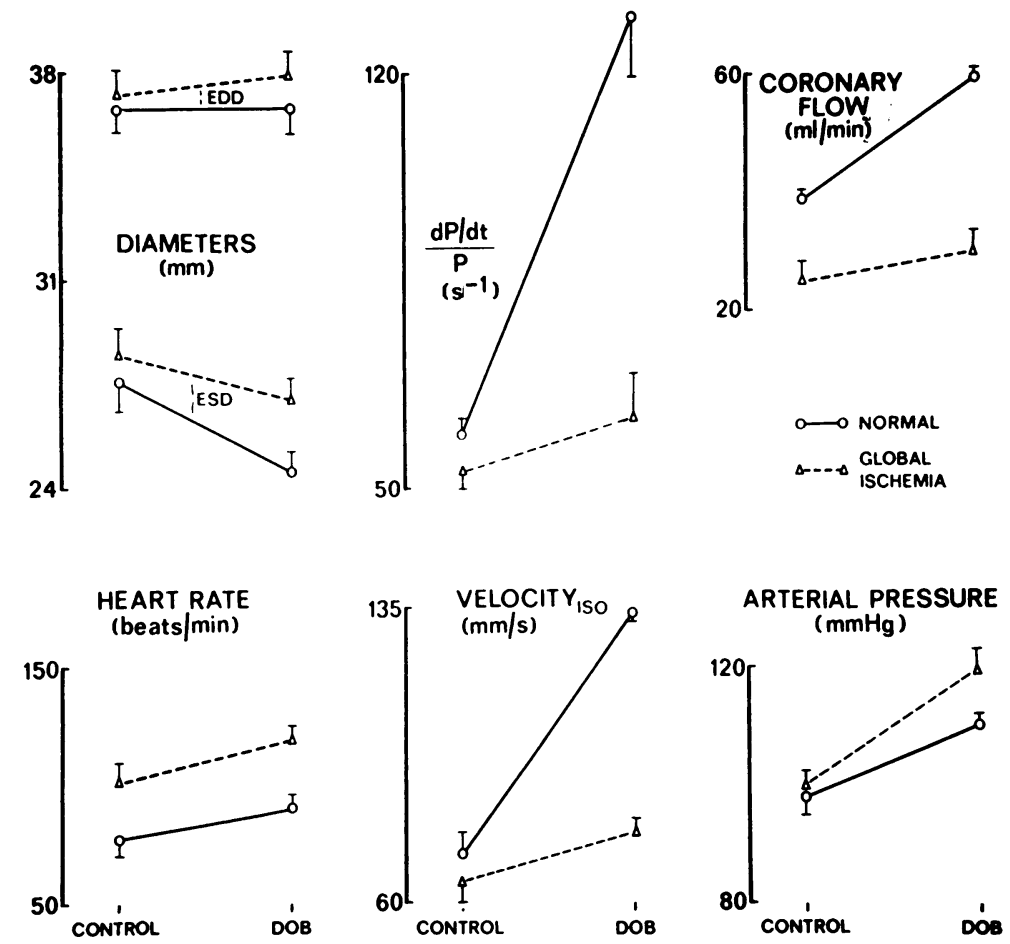

FIGURE 5 Comparison of average \pm SEM values before and during dobutamine (DOB) infusion in the same dogs studied in the nonischemic condition (circles and solid lines) and with moderate global myocardial ischemia at rest (triangles and broken lines). While dobutamine improved LV function considerably in the normal heart, only a marginal response was elicited in the presence of global myocardial ischemia. See Fig. 2 for abbreviations. 


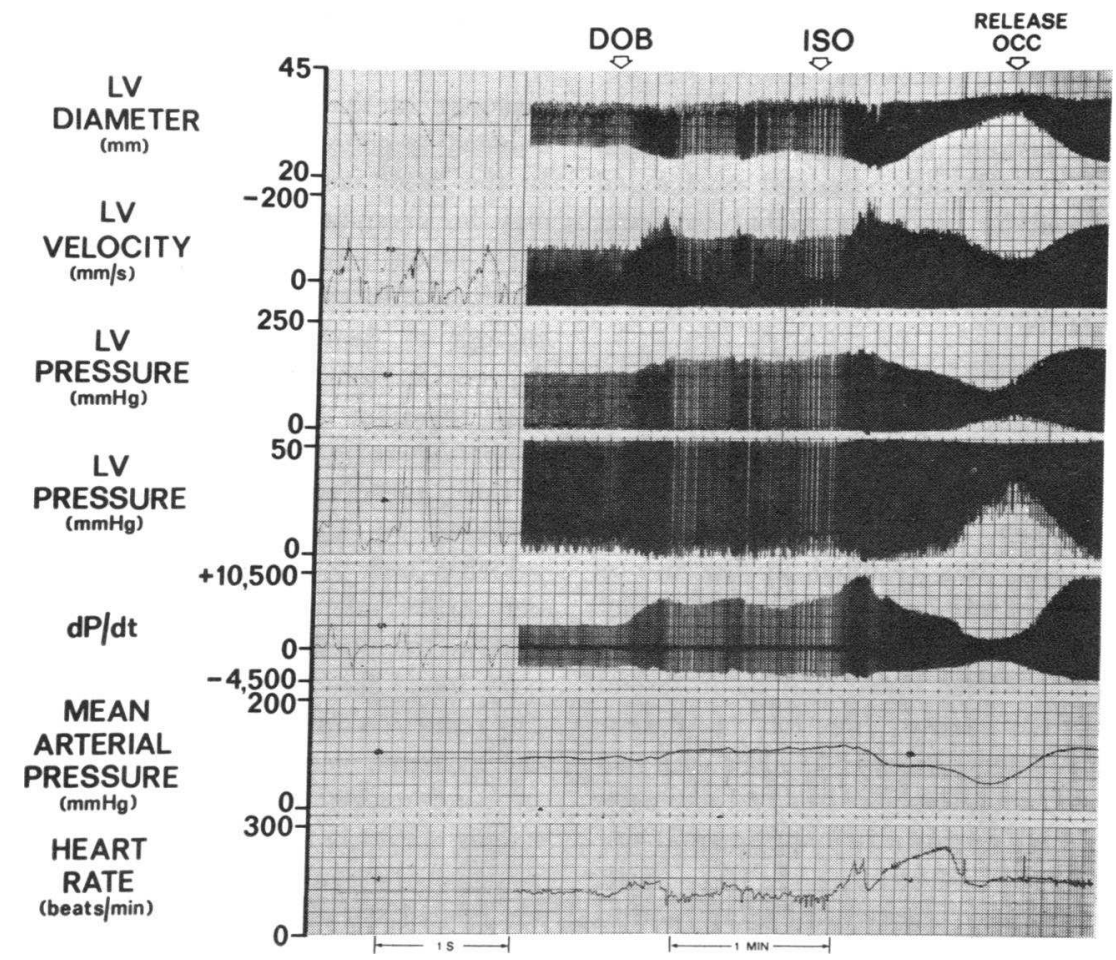

FIGURE 6 Comparison of the responses to dobutamine (DOB) and isoproterenol (ISO) in the same dog with moderate global myocardial ischemia at rest. While LV function was maintained during dobutamine infusion, when isoproterenol was substituted, rapid deterioration in function occurred. With release of coronary obstruction normal response to adrenergic stimulation appeared.

\section{Effects of norepinephrine (five dogs)}

Normal response. In contrast to the other interventions, norepinephrine reduced heart rate and produced the greatest increase in arterial pressure of all of the interventions, while the increases in mean and late diastolic left circumflex coronary blood flows were less than those which occurred with isoproterenol, exercise, and dobutamine (Table II). Also in contrast to the other interventions, mean and late diastolic coronary vascular resistance rose, from $2.41 \pm 0.21$ and $1.85 \pm 0.18$ to $2.90 \pm$ 0.26 and $2.20 \pm 0.20 \mathrm{~mm} \mathrm{Hg} / \mathrm{ml} / \mathrm{min}$, respectively. LV end-diastolic diameter and pressure rose slightly, while LV end-systolic diameter fell. Contractility, as reflected in peak $\mathrm{d} P / \mathrm{d} t, \mathrm{~d} P / \mathrm{d} t / P$, and isolength velocity, rose by similar amounts as with isoproterenol, exercise, and dobutamine (Fig. 7).

Partial left main coronary occlusion. As in the nonischemic heart, norepinephrine infusion reduced heart rate and increased coronary blood flow significantly. LV end-diastolic diameter rose, as did LV end-diastolic pressure, while LV end-systolic diameter, instead of falling, remained constant. Contractility increased substantially $(P<0.01)$ and only slightly less than in the normal heart (Fig. 7).
Effects of nitroglycerin (nine dogs)

Normal response. Nitroglycerin infusion increased heart rate slightly and decreased mean and late diastolic arterial pressures (Table II). Mean and late diastolic left circumflex coronary blood flows rose, while mean

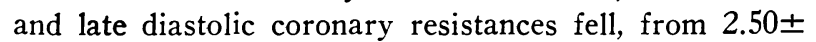
0.13 and $1.87 \pm 0.78$ to $1.62 \pm 0.08$ and $1.12 \pm 0.06 \mathrm{~mm} \mathrm{Hg} /$ $\mathrm{ml} / \mathrm{min}$, respectively. LV end-diastolic and end-systolic diameters and end-diastolic pressure fell substantially (Fig 8); contractility rose slightly.

Partial left main coronary occlusion. After a transient initial improvement in LV function, nitroglycerin infusion produced acute cardiac depression (Fig. 8). Heart rate rose to a greater extent than occurred normally, while mean arterial pressure fell. Coronary blood flow instead of rising, as in the nonischemic heart, fell significantly. LV end-diastolic diameter and pressure, instead of falling as in the nonischemic heart, rose, as did LV end-systolic diameter (Table II). Contractility, instead of rising, fell substantially (Fig. 8). The changes in LV diameters and contractility were all significantly different $(P<0.01)$ from those occurring in the normal heart. 
When arterial pressure was maintained at control levels with inflation of the intra-aortic balloon, the deterioration in LV function was prevented. Coronary blood flow, LV end-diastolic and systolic diameters, $\mathrm{d} P / \mathrm{d} t, \mathrm{~d} P / \mathrm{d} t / P$, and velocity all remained unchanged from the levels achieved by moderate global ischemia alone.

\section{DISCUSSION}

Isoproterenol causes striking improvement in normal cardiac performance through its positive chronotropic, inotropic, and peripheral vasodilating actions mediated by stimulation of beta adrenergic receptors. This salutary effect, which has been observed consistently in the normal circulation (1-3), has resulted in the use of this agent in a variety of clinical conditions in which myocardial function and/or cardiac output are depressed $(24,25)$. However, it has been noted that isoproterenol does not always improve cardiac function in patients with severe coronary artery disease (9-11) and can result in excess lactate formation (12-14) and extension of myocardial injury and necrosis in experimental animals after coronary artery occlusion $(15,16)$. In the present study, isoproterenol exerted differing actions in the normal and ischemic heart. It augmented myo- cardial contractility and heart rate and reduced cardiac size in the normal heart, but it produced a paradoxical response in the presence of moderate global ischemia induced by constriction of the left main coronary artery. In the latter condition, before isoproterenol infusion, it may be presumed that the central obstruction to coronary blood flow was sufficiently severe to result in maximal dilatation of peripheral vessels, but not severe enough to depress LV function seriously. With this degree of global LV ischemia, isoproterenol produced only transient improvement of $\mathrm{LV}$ function, followed almost immediately by the development of acute cardiac failure; end-diastolic cardiac size rose and contractility, reflected by measurements of peak $\mathrm{d} P / \mathrm{d} t, \mathrm{~d} P / \mathrm{d} t / P$, velocity, and the extent of myocardial fiber shortening per stroke, all diminished drastically. It is postulated that in the presence of the central obstruction to coronary blood flow, the reduction in coronary blood flow, the reduction in coronary perfusion pressure caused by the systemic vasodilating effect of the drug, occurring in combination with elevated myocardial oxygen demands (26) as a consequence of isoproterenol's potent positive inotropic and chronotropic actions, produced an intensification of myocardial ischemia, and this resulted in acute depression of $\mathrm{LV}$ performance. The
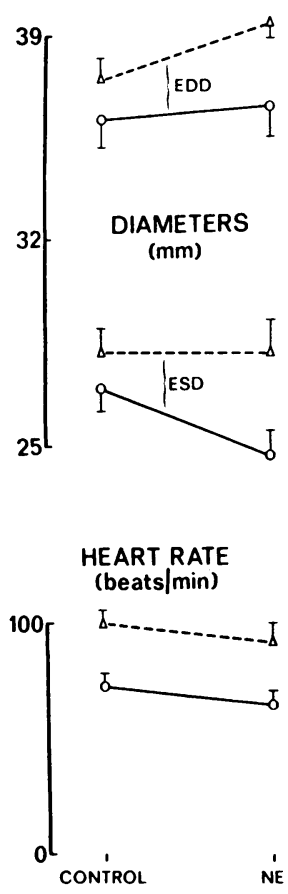
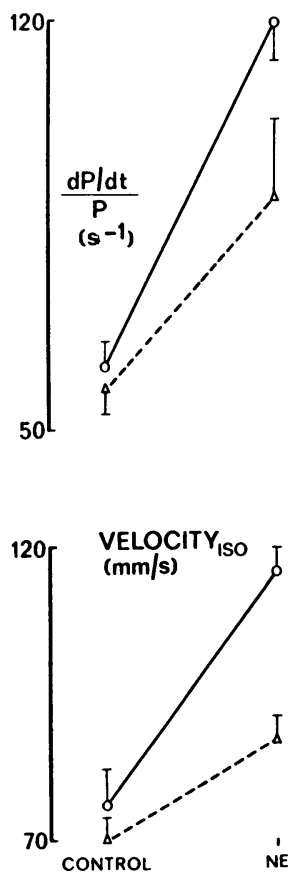
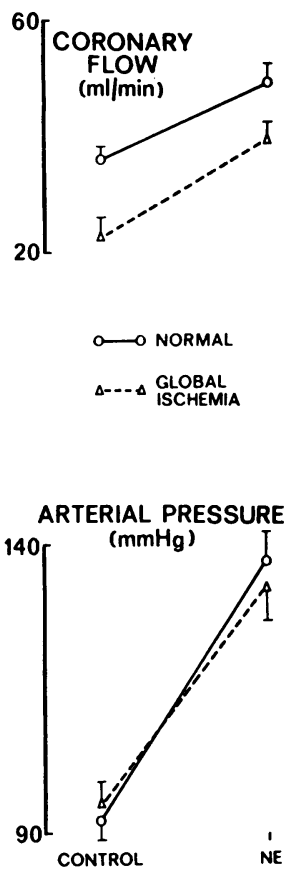

FIGURE 7 Comparison of average \pm SEM values before and during norepinephrine (NE) infusion in the same dogs studied in the nonischemic condition (circles and solid lines) and with moderate global myocardial ischemia at rest (triangles and broken lines). Norepinephrine improved function in both the normal and ischemic myocardium, probably because the marked increase in arterial pressure (right, bottom) permitted an almost normal increase in coronary flow (right, top). See Fig. 2 for abbreviations. 

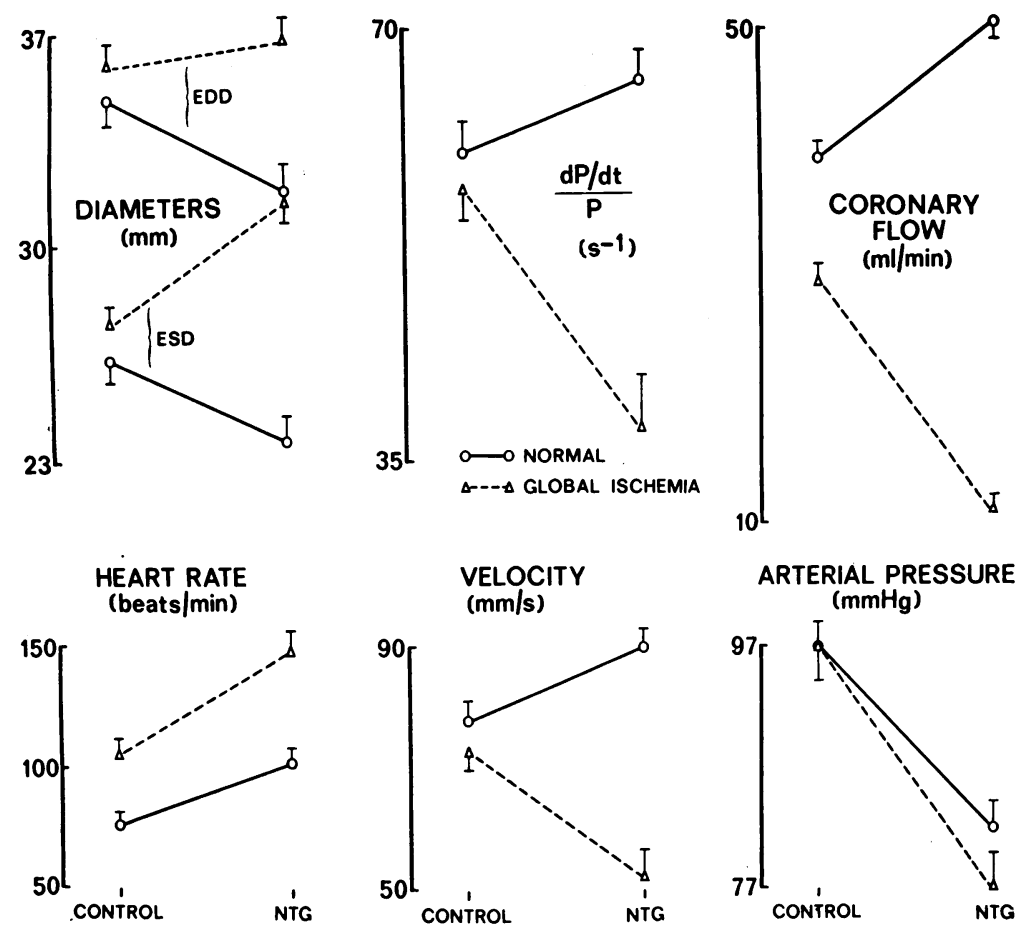

FIGURE 8 Comparison of average \pm SEM values before and during nitroglycerin (NTG) infusion in the same dogs studied in the nonischemic condition (circles and solid lines) and with moderate global myocardial ischemia at rest (triangles and broken lines). Note the paradoxical responses for $\mathrm{LV}$ diameter, $\mathrm{d} P / d t / \mathrm{P}$, velocity, and coronary flow. See Fig. 2 for abbreviations.

production of acute cardiac failure by isoproterenol is dependent both on the dose of the drug and the severity of ischemia, i.e., with less isoproterenol and more intense global ischemia, then similar degrees of acute cardiac depression can be elicited.

Exercise, like isoproterenol, improved cardiac function in the nonischemic heart, but produced a paradoxical action in the presence of mild global myocardial ischemia. However, unlike isoproterenol, exercise did not reduce coronary perfusion pressure in the nonischemic state, but the strongly positive inotropic and chronotropic actions induced by exercise must have raised myocardial oxygen demands above the ability of the obstructed coronary bed to supply the ischemic myocardium, and it is presumed that this again was responsible for the acute depression of cardiac function. With severe exertion, which is accompanied by maximal increases in cardiac rate and contractility (6), acute depression of myocardial function might be elicited even with extremely mild generalized myocardial ischemia. The observations on exercise in which arterial pressure remained constant in the nonischemic heart, together with those in the ischemic heart in which arterial pressure was maintained by inflating the intra-aortic balloon during isoproterenol infusion, an intervention which delayed but ultimately did not prevent the isoproterenol-induced depression of cardiac performance, demonstrate that the maintenance of arterial pressure, while helpful, is not sufficient to prevent the deleterious effects of interventions that exert potent positive inotropic and chronotropic actions in the presence of global myocardial ischemia.

On the other hand, the experiments with nitroglycerin demonstrated the importance of maintaining coronary perfusion in the ischemic heart. Nitroglycerin normally increases coronary blood flow as a consequence of its direct coronary vasodilating effect and, secondarily, through stimulation of myocardial metabolism resulting from its positive inotropic and chronotropic effects which are induced reflexly ( 7 ). In the presence of global myocardial ischemia, nitroglycerin increased end-diastolic cardiac size and pressure and decreased contractility and stroke excursion. It appears most likely that it was the reduction in aortic, i.e. coronary perfusion pressure after nitroglycerin in the presence of coronary obstruction, rather than the slight increase in contractility and heart rate, that exerted the more severe deleterious influence, since returning perfusion pressure to control levels with aortic balloon inflation could prevent the depression of cardiac performance. It is also possible that 
a "steal," or redistribution of myocardial blood flow from the endocardium to the epicardium, which nitroglycerin has been shown to induce in the presence of myocardial ischemia (27), may have been a possible additional factor resulting in the intensification of ischemia and depression of LV function.

Dobutamine, a recently developed inotropic agent, preferentially stimulates beta adrenergic receptors responsible for increasing myocardial contractility while producing relatively little effect on heart rate and arterial pressure ${ }^{2}$ (5). According to the hypothesis advanced, a reduction in coronary perfusion pressure or an increase in myocardial metabolic demand is deleterious in the presence of a central obstruction to coronary blood flow and results in the appearance, or the intensification, of global myocardial ischemia. Accordingly, dobutamine should have been tolerated better than isoproterenol. This was, in fact, noted, i.e., dobutamine in doses that resulted in inotropic responses equivalent to those induced by isoproterenol caused no deterioration of $\mathrm{LV}$ function in the presence of partial left main coronary artery occlusion. When, under these circumstances, isoproterenol was substituted for dobutamine, acute cardiac failure developed (Fig. 6). This should not be interpreted to indicate that dobutamine can be administered with impunity in the presence of diffuse myocardial ischemia, since with more severe restriction of coronary blood flow or a greater dose of dobutamine, a paradoxical negative inotropic response was elicited. However, these results suggest that for an equi-inotropic effect, the likelihood of developing or intensifying ischemia is much less with dobutamine than with isoproterenol, since dobutamine can exert a similar positive inotropic action with less of isoproterenol's undesirable side effects, i.e., hypotension and tachycardia.

The results of the experiments with norepinephrine further corroborated our hypothesis. While augmenting myocardial contractility, norepinephrine raises arterial pressure through a powerful alpha adrenergic stimulating action and induces bradycardia through baroreceptor reflexes. Accordingly, it followed that norepinephrine's response was not altered profoundly by the partial occlusion of the left main coronary artery (Fig. 7). The increase in myocardial contractility that occurred was probably made possible by the increase in coronary flow that accompanied the increase in coronary perfusion pressure. Similar conclusions were reached by Mueller, Ayers, Gregory, Giannelli, and Grace, who reported beneficial results with norepinephrine in patients with myocardial ischemia, while noting that isoproterenol increased lactate production (14). These results should not be interpreted to mean that norepinephrine is clearly the best therapeutic agent to use in patients with depressed myocardial function due to diffuse myocardial ischemia, since the drug produces alpha adrenergic vaso- constriction in the coronary (4) as well as other peripheral beds (28) through stimulation of alpha adrenergic receptors, and it frequently produces arrhythmias as well.

In conclusion, in the presence of moderate global myocardial ischemia produced by obstruction of the left main coronary artery when coronary blood flow cannot increase, positive inotropic and chronotropic stimuli, by increasing myocardial oxygen demands, unfavorably influence the balance between oxygen supply and demand, thereby intensifying ischemia and resulting in a paradoxical deterioration of cardiac function. Hypotension, which diminishes coronary perfusion pressure and consequently coronary blood flow, is also detrimental in the presence of global myocardial ischemia. Thus, isoproterenol's strongly positive inotropic and chronotropic effects, in combination with its peripheral vasodilating action which reduces coronary perfusion pressure, makes this agent potentially hazardous in the presence of global ischemia, a condition which may occur in patients with diffuse multivessel coronary artery disease. The potent positive inotropic and chronotropic effects induced by exercise and the hypotensive action of nitroglycerin also elicit paradoxical responses which result in deterioration of ventricular function. The administration of a drug, such as dobutamine which increases myocardial contractility in the normal heart without affecting arterial pressure or heart rate substantially, has little effect on $\mathrm{LV}$ function in the presence of moderate global ischemia but can be deleterious in the presence of severe global ischemia. Norepinephrine, on the other hand, which increases coronary perfusion pressure along with contractility, improves cardiac performance in the presence of moderate global ischemia as well as in the nonischemic heart.

It is always difficult to extrapolate from the results of a study in an experimental animal model of myocardial ischemia to the patient with severe diffuse coronary artery disease. Nevertheless, these results suggest that in the presence of global ischemia, beta adrenergic-stimulating drugs may either be relatively ineffective in improving myocardial contractility, or actually may be deleterious.

Tachycardia and hypotension also impair cardiac performance, findings which further demonstrate the potential hazards of using isoproterenol, as well as the undesirability of the hypotensive effect of nitroglycerin in the presence of global myocardial ischemia. The high oxygen cost of tachycardia was an important factor in determining the difference in response of the ischemic heart to isoproterenol and exercise, which induced tachycardia on the one hand, and to dobutamine and norepinephrine, on the other hand, where little or no tachycardia occurred. Norepinephrine, by increasing arterial pressure and coronary blood flow, improves cardiac 
peformance, which suggests that in the presence of acute global myocardial ischemia, the major effort should be directed towards increasing coronary flow through stenosed coronary vessels by elevating systemic pressure, rather than simply towards improving the myocardial contractile state, which cannot occur without an increase in coronary blood flow.

\section{ACKNOWLEDGMENTS}

The technical assistance of $\mathrm{T}$. Manders, the help in preparation of the manuscript by V. Fowler, and the generous supplies of dobutamine from Eli Lilly Company are appreciated. We also appreciate the use of the facilities of the New England Regional Primate Research Center, Southborough, Mass., where a portion of this study was conducted.

This study was supported by U. S. Public Health Service Grants HL 15416 and HL 1043609, NIH NHLI Contract 72-2949, and grants from The John A. Hartford Foundation and the Eli Lilly Co.

\section{REFERENCES}

1. Weissler, A. M., J. J. Leonard, and J. V. Warren. 1959. The hemodynamic effects of isoproterenol in man. With observations on the role of the central blood volume. J. Lab. Clin. Med. 53: 921-925.

2. Dodge, H. T., J. D. Lord, and H. Sandler. 1960. Cardiovascular effects of isoproterenol in normal subjects and subjects with congestive heart failure. Am. Heart $J$. 60: $94-105$

3. Krasnow, N., E. L. Rolett, P. M. Yurchak, W. B. Hood, Jr., and R. Gorlin. 1964. Isoproterenol and cardiovascular performance. Am. J. Med. 37: 514-525.

4. Vatner, S. F., C. B. Higgins, and E. Braunwald. Coronary and left ventricular dynamic effects of norepinephrine in conscious dogs. Circ. Res. In press.

5. Vatner, S. F., R. J. McRitchie, and E. Braunwald. Effects of dobutamine on left ventricular performance, coronary dynamics, and distribution of cardiac output in conscious dogs. J. Clin. Invest. 53: 1265-1273.

6. Vatner, S. F., D. Franklin, C. B. Higgins, T. Patrick, and E. Braunwald. 1972. Left ventricular response to severe exertion in untethered dogs. J. Clin. Invest. 51: 3052-3060.

7. Vatner, S. F., C. B. Higgins, R. W. Millard, and D. Franklin. 1972. Direct and reflex effects of nitroglycerin on coronary and left ventricular dynamics in conscious dogs. J. Clin. Invest. 51: 2872-2882.

8. Maroko, P. R., P. Libby, and E. Braunwald. 1973. Effect of pharmacologic agents on the function of the ischemic heart. Am. J. Cardiol. 32: 930-936.

9. Elliott, W. C., and R. Gorlin. 1966. Isoproterenol in treatment of heart disease. Hemodynamic effects in circulatory failure. JAMA J. Am. Med. Assoc. 197: 315-320.

10. Cohen, L. S., W. C. Elliott, E. L. Rolett, and R. Gorlin. 1965. Hemodynamic studies during angina pectoris. Circulation. 31 : 409-416.

11. Gunnar, R. M., H. S. Loeb, R. J. Pietras, and J. R. Tobin, Jr. 1967. Ineffectiveness of isoproterenol in shock due to acute myocardial infarction. JAMA J. Am. Med. Assoc. 202: 1124-1128.

12. Herman, M. V., W. C. Elliott, and R. Gorlin. 1967. An electrocardiographic, anatomic, and metabolic study of zonal myocardial ischemia in coronary heart disease. Circulation. 35: 834-846.

13. Cohn, P. F., and R. Gorlin. 1972. Abnormalities of left ventricular function associated with the anginal state. Circulation. 46: 1065-1078.

14. Mueller, H., S. M. Ayers, J. J. Gregory, S. Giannelli, Jr., and W. J. Grace. 1970. Hemodynamics, coronary blood flow, and myocardial metabolism in coronary shock; response to $l$-norepinephrine and isoproterenol. J. Clin. Invest. 49: 1885-1902.

15. Maroko, P. R., J. K. Kjekshus, B. E. Sobel, T. Watanabe, J. W. Covell, J. Ross, Jr., and E. Braunwald. 1971. Factors influencing infarct size following experimental coronary artery occlusions. Circulation. 43: 67-82.

16. Maroko, P. R., P. Libby, J. W. Covell, B. E. Sobel, J. Ross, Jr., and E. Braunwald. 1972. Precordial S-T segment elevation mapping: an atraumatic method for assessing alterations in the extent of myocardial ischemic injury. The effects of pharmacologic and hemodynamic interventions. Am. J. Cardiol. 29: 223-230.

17. Franklin, D. E., N. W. Watson, K. E. Pierson, and R. L. Van Citters. 1966. Technique for radio telemetry of blood-flow velocity from unrestrained animals. $\mathrm{Am}$. J. Med. Electron. 5: 24-28.

18. Vatner, S. F., D. Franklin, and R. L. Van Citters. 1970. Simultaneous comparison and calibration of the Doppler and electromagnetic flowmeters. J. Appl. Physiol. 29: 907-910.

19. Patrick, T. A., S. F. Vatner, W. S. Kemper, and D. Franklin. Telemetry of left ventricular diameter and pressure measurements in unrestrained animals. $J$. Appl. Physiol. In press.

20. Suga, H., and K. Sagawa. 1974. Assessment of absolute volume from diameter of the intact canine left ventricular cavity. J. Appl. Physiol. 36: 496-499.

21. Glick, G., E. H. Sonnenblick, and E. Braunwald. 1965. Myocardial force-velocity relations studied in intact unanesthetized man. J. Clin. Invest. 44: 978-988.

22. Mason, D. T., E. Braunwald, J. W. Covell, E. H. Sonnenblick, and J. Ross, Jr. 1971. Assessment of cardiac contractility; the relation between the rate of pressure rise and ventricular pressure during isovolumic systole. Circulation. 44: 47-58.

23. Snedecor, G. W., and W. G. Cochran. 1967. Statistical Methods. Iowa State University Press, Ames. 6th edition. 91-98.

24. Corday, E., and R. C. Lillehei. 1969. Controversies in cardiology. Pressor agents in cardiogenic shock. $\mathrm{Am}$. J. Cardiol. 23: 900-910.

25. Smith, H. J., A. Oriol, J. Morch, and M. McGregor. 1967. Hemodynamic studies in cardiogenic shock. Treatment with isoproterenol and metaraminol. Circulation. 35 : 1084-1091.

26. Braunwald, E. 1971. Control of myocardial oxygen consumption: physiologic and clinical considerations. $\mathrm{Am}$. J. Cardiol. $27: 416-432$

27. Forman, R., E. S. Kirk, J. M. Downey, and E. H. Sonnenblick. 1973. Nitroglycerin and heterogeneity of myocardial blood flow. Reduced subendocardial blood flow and ventricular contractile force. $J$. Clin. Invest. 52: 905-911.

28. Berne, R. M., W. K. Hoffman, Jr., A. Kagan, and M. N. Levy. 1952. Response of the normal and denervated kidney to l'epinephrine and l'nor-epinephrine. Am. J. Physiol. 171: 564-571. 